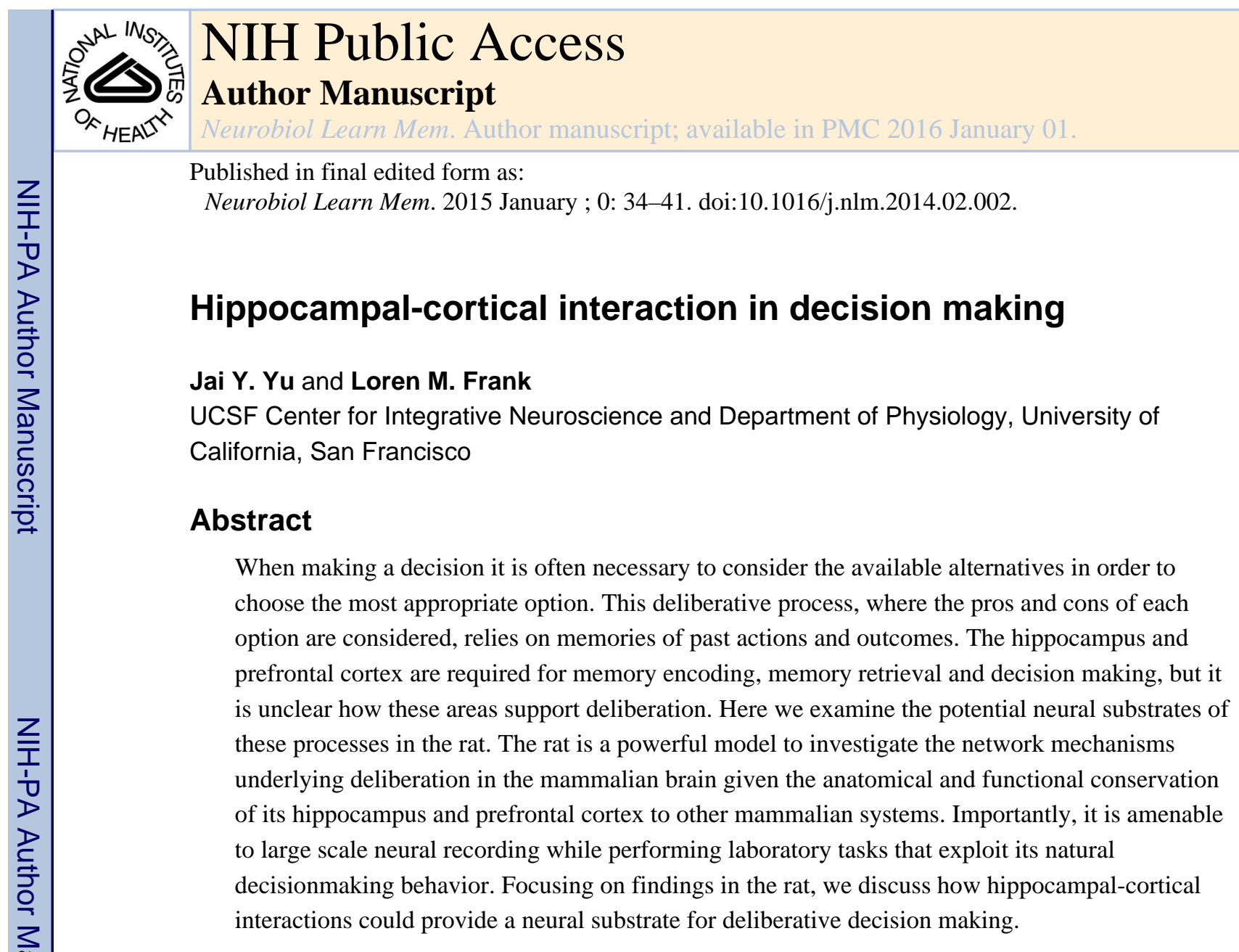

\title{
Deliberation in the rat
}

Behavioral observations in naturalistic settings demonstrated that the brown rat, Rattus norvegicus, has remarkable spatial memory (Calhoun 1963; Telle 1966). Individuals can remember locations of food sources, paths, predators and competitors in an environment and use this information for efficient foraging. Moreover, natural environments are complex and change over time. The rat needs to adapt to any changes it encounters, such as the presence of predators and obstacles on its foraging routes. As a result, relying solely on reflexive or habitual routines is insufficient for successful foraging in the long term. Memory, in particular the ability to learn spatial relationships and to modify stored representations when the world changes, is therefore critical for a foraging rodent to obtain food while avoiding danger.

Making navigational decisions based on stored memories requires planning and evaluation of potential trajectories based on information about past foraging experiences. This representation of the external world stored in memory has been referred to as the "cognitive map" (Tolman et al. 1946; Tolman 1948). Navigational decision making can therefore be seen as an internal deliberation process whereby different routes through the animal's

(C) 2014 Elsevier Inc. All rights reserved.

Publisher's Disclaimer: This is a PDF file of an unedited manuscript that has been accepted for publication. As a service to our customers we are providing this early version of the manuscript. The manuscript will undergo copyediting, typesetting, and review of the resulting proof before it is published in its final citable form. Please note that during the production process errors may be discovered which could affect the content, and all legal disclaimers that apply to the journal pertain. 
cognitive map are evaluated. In this type of decision making, the animal considers the action and consequences of multiple options, weighing up the pros and cons in order to decide on the most suitable option.

We expect that this type of deliberation is most important during the learning of new routes and following changes to the environment. In these situations, no single option stands out as being correct and therefore many alternatives need to be considered. Many aspects of natural foraging behavior are captured in laboratory behavior paradigms that requires a rat to find food reward by navigating along defined paths or in an arena. Thus, these paradigms are well suited to investigate deliberation in a spatial context that is ethologically relevant. Indeed, a rat performing a laboratory task that requires a choice between different arms of a maze pauses briefly at maze choice points and turn its head back and forth to scan the possible routes before choosing one, a behavior termed vicarious trial and error (Muenzinger and Gentry 1931; Tolman 1938; Johnson and Redish 2007). This behavior is most frequent in the learning phase of the task when the rat is still unsure of the rules.

\section{Neural signatures of deliberation}

The processes of deliberation include the initial formation of memory, its subsequent recall to provide the options for deliberation and the comparison and evaluation of these options. These processes depend on a number of brain regions, including the hippocampus and the prefrontal cortex (PFC). While patterns of activity important for memory formation have been identified in the hippocampus, the neural substrates and patterns of activity that support the recall and evaluation of choice options based on memory remain somewhat unclear. We will review findings in the fields of memory and decision making and propose candidate neural mechanisms in the hippocampus and PFC to support these steps of deliberation.

To find the pattern of neural activity and mechanisms mediating different steps of deliberation, we need to identify the prerequisites necessary to support deliberation. Since deliberation is more important during learning, we expect the pattern of activity to be more prominent during this period. The pattern of neural activity also needs to occur at locations where deliberation is important. These locations are where a rat needs to plan its next trajectory, which include the starting point and subsequent choice points. The content of the pattern of activity should also contain information useful for the decision. In the case of navigational decisions, the pattern of activity should contain spatial representations not limited to the current location but instead representations of extended trajectories or remote locations of interest. Lastly, the pattern of activity must be required for decisions that require deliberation. Having these requirements in mind, we will explore various patterns of neural activity in the hippocampus and the PFC and determine if they are likely candidates for deliberation.

\section{Hippocampal contribution to deliberation}

If experience is to be used in the future for making decisions, it must be encoded and stored. Strong neural correlates of memory encoding processes can be found in the hippocampus across species (Squire 1992). In the rat, the hippocampus forms representations of experience that are expressed through the sequential firing of unique ensembles of 
pyramidal neurons as the animal explores an environment. The pyramidal neurons are often active at specific spatial locations in the environment, giving rise to their name: "place cells" (O'Keefe and Dostrovsky 1971). The location in which a place cell fires is called its "place field". However, place cells represent much more than place. Numerous studies have shown that these neurons can respond to a complex combination of spatial and non-spatial information including external sensory stimuli and aspects of task relevant behaviors (Wible et al. 1986; Eichenbaum et al. 1987; Wiener et al. 1989; Sakurai 1996; Frank et al. 2000; Wood et al. 2000; Ferbinteanu et al. 2003; Pastalkova et al. 2008; MacDonald et al. 2011). Taking account of these findings, the ensemble activity of "place cells" in the hippocampus is perhaps best described as encoding a moment by moment representation of different dimensions of experience (Eichenbaum et al. 1999).

\section{Theta oscillations}

Physiologically, hippocampal information processing can be characterized as a continuum of states that appears to reflect the relative dominance of processed sensory input and stored representations (Kemere et al. 2013). During periods of active exploration, processed sensory input drives coordinated neuronal activity in the hippocampus, and is associated with synchronous oscillation in the $7-10 \mathrm{~Hz}$ range, termed theta (Buzsaki 2002; Hasselmo and Stern 2013). Theta oscillations are most prominent during locomotion and less so during pauses in activity.

During periods of theta oscillation, each place cell fires at a preferred phase of each period. As the animal traverses the place field of a place cell, the phase at which spikes fire gradually shifts earlier with each theta cycle, a phenomenon called theta precession(O'Keefe and Recce 1993; Skaggs and McNaughton 1996). Thus, activity of place cells during theta oscillation seems well suited to encode information about the rat's current location and a local trajectory on a rapid timescale. Having a representation of the current location is necessary for the animal to determine if it is in a place where a decision needs to be made. This information could also be used by other brain areas to monitor if the current course of action matches the choice made in the original decision.

With respect to deliberation, we expect to observe representations of potential trajectories beyond the current location of the rat. Representations of locations ahead of the rat during theta have been reported at trajectory choice points and correspond with vicarious trial and error behavior (Johnson and Redish 2007; Gupta et al. 2012). This study suggests theta oscillation during pauses at a choice point is a period when place cells momentarily encode non-local representations and could reflect the exploration of future trajectories. At the same time, these sequences have been seen in the context of tasks where a familiar environment is altered to contain a different series of choice points, and further work will be required to determine the characteristics of these sequences in other circumstances.

\section{Sharp-wave ripples}

At low movement speeds and when a rat is not actively exploring, another network pattern of hippocampal activity known as sharp-wave ripples (SWRs) becomes prominent. SWRs are brief high frequency oscillations, between $150-250 \mathrm{~Hz}$ (Buzsaki 1986) originating from 
the CA3 region and propagating to the CA1 region of the hippocampus (Buzsaki 1986; Csicsvari et al. 2000). During this period, ensembles of pyramidal neurons become briefly reactivated (Wilson and McNaughton 1994; Skaggs and McNaughton 1996; Kudrimoti et al. 1999; Foster and Wilson 2006; Jackson et al. 2006; Diba and Buzsaki 2007; Davidson et al. 2009). Cells whose activity would span many seconds as the animal explores, during theta oscillation, are reactivated within a few hundred milliseconds. Importantly, ensemble firing on this fast time scale often preserves the original temporal relationship between cells. Relating the sequence of firing of individual cells and their place fields in an environment reveals representations of actual trajectories traversed by the animal (Lee and Wilson 2002; Foster and Wilson 2006; Diba and Buzsaki 2007). These observations provide strong evidence that during SWRs the hippocampus reactivates a time-compressed version of past experiences.

SWR replay events have been linked to the offline strengthening of cortical representations of memory through repeated activation of cortical ensembles during sleep or inactivity (Buzsaki 1996; Frankland and Bontempi 2005; Diekelmann and Born 2010; O'Neill et al. 2010; Girardeau and Zugaro 2011). Since the first reports of hippocampal replay during sleep, replay has subsequently been observed to occur frequently during active behavior (Kudrimoti et al. 1999; Foster and Wilson 2006; Jackson et al. 2006; Diba and Buzsaki 2007; Davidson et al. 2009; Karlsson and Frank 2009; Dupret et al. 2010). On a network level, the reactivation of memory sequences during SWRs could provide a convenient mechanism to quickly recall memories during the awake state (Carr et al. 2011).

The dynamics of SWRs and the behavioral correlate of deliberation, vicarious trial and error, are similar: both are initially more frequent and then decrease with learning (Muenzinger 1938; Jadhav et al. 2012). When a rat is first exposed to a novel task, SWRs are prevalent. As the animal learns and becomes familiar with the task, the number of SWRs gradually decreases (Cheng and Frank 2008; O'Neill et al. 2008; Singer and Frank 2009). When a change in the task is introduced, such as exposing the rat to a second novel environment, an increase in the number of SWRs is again observed which then decays with familiarization (Karlsson and Frank 2008). This is consistent with deliberation playing a more important role during early learning, before schemas and habits form. Further, SWRs are more prevalent at low speeds, consistent with deliberation, although they can be seen during higher speed locomotion as well (O'Neill et al. 2006; Cheng and Frank 2008), raising the possibility that in some cases SWR activity could contribute to deliberation during movement.

It is unknown what environmental or behavioral cues trigger SWRs but the locations where SWRs tend to occur may offer some clues. Many SWRs occur at path choice points (Karlsson and Frank 2009; Jadhav et al. 2012), which are also locations where vicarious trial and error is reported (Muenzinger 1938). Other locations where SWRs occur are the destination of a trajectory, usually the reward location, and during brief pauses in locomotion (Kudrimoti et al. 1999; Foster and Wilson 2006; Jackson et al. 2006; Diba and Buzsaki 2007; Davidson et al. 2009; Singer and Frank 2009; Dupret et al. 2010). These are all locations where decisions are made about where to go next in order to find reward. We 
suggest that activity at these locations corresponds to a decision making state that biases the hippocampus to initiate SWRs.

If SWRs are critical for learning and deliberation, the reactivated memory should encode trajectories or include locations relevant for active navigation. One important location, useful for the decision at hand, is the current location of the rat. This is in fact the case, as decoding of place cell reactivation during SWRs shows replayed trajectories are biased to include the current location of the animal (Diba and Buzsaki 2007; Davidson et al. 2009; Karlsson and Frank 2009; Pfeiffer and Foster 2013). Mechanistically, the place cell coding for the animal's current location is active and could seed the activation of a chain of interconnected place cells, giving rise to trajectories starting from or pointing to the current location. This network property provides a convenient means to initiate deliberation with relevant choice options from the current location. The lengths of replayed trajectories have been reported to span several meters, which represent realistic trajectories in the environment (Davidson et al. 2009; Pfeiffer and Foster 2013). Long trajectories can also be represented across multiple SWRs, with each SWR reactivating a ion of the entire trajectory (Davidson et al. 2009). This suggests each SWR encodes a discrete trajectory, similar to an episode of an experience.

The goal location is another important feature when planning trajectories since a desirable trajectory should end at the goal, normally where a reward is found. Evidence for goal location representation comes from tasks where a rat is allowed to explore an open field to find a hidden reward, without having to follow predefined tracks (Dupret et al. 2010; Pfeiffer and Foster 2013). Since these reward locations change over time, the rat needs to actively form and use memory in order to efficiently obtain reward. Awake replay events that occur during these tasks reactivate place cells that represent reward locations (Dupret et al. 2010) and contain trajectories that can be biased to terminate at the goal (Pfeiffer and Foster 2013). This suggests replay events encode trajectories that re useful for making navigational decisions towards a goal.

We have investigated the content of replay events with respect to deliberation in our Wtrack alternation task. In this task the rat must learn to visit each of the side arms from the center arm of the maze in an alternating pattern (Figure 1). To perform the task correctly, the rat needs to learn and apply two rules, each appropriate for specific locations. When the rat is on the center arm, it has to make an "outbound" decision. This involves choosing the side arm that was not visited in the previous trial. To apply the rule correctly, the rat needs to recall from memory the arm visited in the past trial to choose the correct arm for the next trial. When the rat is on either side arm, it has to make an "inbound" decision, which involves returning to the center. The "inbound" decision requires the rat to always return to the center arm when it is on either of the side arms. The "inbound" decision is more similar to an association between place and action since it does not depend on the history of previous visits.

Deliberation implies choosing between different options. This is also evident in the range of replayed trajectories decoded during SWRs. Replayed trajectories are not only limited to those eventually taken by the rat but also those not taken. For "outbound" decisions on the 
W-track, replay of trajectories for both the correct and incorrect arm occur equally often (Singer et al. 2013). In the open field foraging task, the replayed trajectories are not replicas of the actual future trajectory but are enriched for ones that point in the direction of the reward (Pfeiffer and Foster 2013). Both findings suggest replay events provide potential trajectory options, not exclusively the one that is taken.

Even more intriguing are findings that replayed trajectories could reflect trajectories from another similar environment (Karlsson and Frank 2009) or in rare instances, novel routes in the local environment that have not been experienced by the animal (Gupta et al. 2010). In humans, the hippocampus is implicated in the retrieval of memories that are considered remote, such as autobiographical memory (Nadel et al. 2003; Addis et al. 2007). These observations suggest the hippocampus could allow exploration of potential choices far beyond what is local or purely based on recent experience. This mechanism could be important especially in novel situations when the immediate course of action is not apparent. This process shares hallmarks of imagination, the mental function where existing memories are arranged to form simulations of novel situations. The ability of the hippocampus to reactivate or rearrange existing experiences to generate novel sequences has been suggested to support imagination and creativity (Dudai and Carruthers 2005; Schacter and Addis 2007; Schacter et al. 2007; Buckner 2010). By accessing memories of remote experiences that share even minimal similarities with the current experience, or even combining memory to form novel situations, the hippocampus could provide options for the brain to try out. Thus, the memory functions of the hippocampus may be repurposed in to provide a flexible system that would support rapid behavioral adaptation and access to a wide range of possible choices.

Finally, results from our laboratory provide a direct link between SWRs and memory-guided decision making. In our study we interrupted SWRs while a rat learned the W-track alternation task (Jadhav et al. 2012). When SWRs are interrupted while the rat is learning the task, performance on the outbound trials is impaired. In the context of deliberation, disruption of SWRs may have prevented the recall of choice options through replay (Figure 2). This is especially important during the learning stage as the rat has not acquired the alternation rule and is unsure of whether to choose the left or right arm. Normally, SWRs may reactivate place cell sequences that correspond to trajectories to each of the side arms, both potential future alternatives trajectories. When SWRs are disrupted, memory for the alternatives would not be available to inform the decision. Interestingly, unlike the impairment in "outbound" performance, SWR interruption does not impair performance on the "inbound" trials. This result may be explained by the "inbound" rule not needing information from memory about the previous trial. Deliberation is not required since a place-response rule of always return to center arm if on the outside arm is sufficient.

The results from studies described above, involving different tasks with a wide variety of spatial topologies, suggest memory replay during SWRs fulfills the requirements for a neural signature that supports deliberation. We suggest that replay events are a manifestation of the recall of episodes of past experience that form the alternatives for the exploration of potential future choices. Our findings that, during learning, replay is not consistently biased towards the correct versus the incorrect future option (Singer et al. 2013) imply that some 
other brain areas must be required to evaluate these possibilities to determine which one represents the best choice. Regions of the PFC are likely to be critical for this evaluation.

\section{Hippocampal-cortical interaction and deliberation}

The PFC consists of a set of anatomically interconnected regions with similar patterns of connectivity across species (Uylings and van Eden 1990; Uylings et al. 2003; Seamans et al. 2008). These regions have been shown to be important in adaptive behavior and decision making (Chudasama 2011; Kesner and Churchwell 2011; Euston et al. 2012) and rats with inactivated medial PFC and hippocampus are unable to make correct choices between rewarded or unrewarded locations based on memory (Kesner 1989; Floresco et al. 1997; Ragozzino et al. 1998; Seamans et al. 2008).

The areas of the rodent PFC likely to be important for deliberation include the anterior cingulate, medial and ventral medial PFC; also referred to as the pre- and infralimbic cortices (Kesner and Churchwell 2011). Anatomically, the hippocampus sends projections from CA1 and subiculum directly to the prelimbic cortex (Swanson and Cowan 1977; Jay et al. 1989; Van Groen and Wyss 1990; Verwer et al. 1997; Degenetais et al. 2003; Tierney et al. 2004) and also indirect connections from CA1 via the anterior thalamic nuclei (Cenquizca and Swanson 2007; Prasad and Chudasama 2013; Varela et al. 2013). The direct pathway consists of projections from a population of hippocampal pyramidal cells (Klausberger and Somogyi 2008) that synapse onto both pyramidal (Carr and Sesack 1996) and local inhibitory interneurons (Gabbott et al. 2002) in the PFC. Consistent with the diversity of targets, anaesthetized experiments have shown PFC network responses to hippocampal stimulation is complex (Laroche et al. 1990; Jay et al. 1992; Takita et al. 2013).

\section{Hippocampal - PFC interactions during theta oscillations}

The hippocampus and PFC interact at theta frequencies during exploration. Some PFC units show phase locking to hippocampal theta oscillation and moreover fire after hippocampal units (Siapas and Wilson 1998; Hyman et al. 2005). Theta phase precession, similar to that seen in hippocampal place cells, has also been observed in PFC units (Jones and Wilson 2005a). This suggests a potential mechanism where information is exchanged through oscillatory synchrony between hippocampus and PFC during behavior. The importance of theta modulated firing in the PFC is supported by observations that coherence in the theta frequency range of the local field potential (LFP) between the two regions increases at the choice point of a maze, where the animal has to choose between arms (Jones and Wilson 2005b; Benchenane et al. 2010; Remondes and Wilson 2013).

Importantly, this increase in coherence is correlated with performance and is significantly higher after the animal had learned the rule. Once behavioral performance plateaus, the increase in coherence is higher preceding the choice point for a correct choice (Jones and Wilson 2005b). Based on these findings, we suggest that theta coherence reflects transmission of information about current location and local trajectory from the hippocampus to the PFC, perhaps to ensure a learned rule is appropriately executed given the current behavioral state and physical location of the animal. 
The only instance where activity during theta is thought to be consistent with deliberation is that place cells with place fields a head of the animal's position become active at choice points during vicarious trial and error in the absence of SWRs (Johnson and Redish 2007). What effect these non-local activity in the hippocampus has on the PFC remains to be determined. This could be an intriguing mechanism for hippocampal-cortical interaction during theta that supports the exploration of future trajectories but further characterization is needed to fully understand the function of these representations.

\section{Hippocampal - PFC Interaction during Sharp-wave ripples}

We suggest that theta-related coherence may be better suited to support behavior in well learned tasks when deliberation is no longer necessary. We therefore consider activity in the PFC time locked to hippocampal SWRs as a potential candidate for deliberative decision making. At present, however, coordinated activity between PFC and hippocampus at the time of SWRs has been described in detail only during sleep. The PFC shows time locked LFP changes to SWRs depending on sleep state (Siapas and Wilson 1998; Sirota et al. 2003; Battaglia et al. 2004; Molle et al. 2006; Wierzynski et al. 2009). Similar to the hippocampus, both the presence of cell assemblies representing progression through a task (Fujisawa et al. 2008) and the reactivation of these cell ensemble sequences have been reported in the PFC (Euston et al. 2007). Importantly, specific representations in the PFC can be observed at the time of hippocampal SWRs (Peyrache et al. 2011). These observations suggest that SWRs can drive PFC activity during sleep, and suggest that this could also occur during the awake state. That possibility is consistent with a recent study that reported an increase in BOLD activity of primate PFC following SWRs and in one animal this was observed in the awake state (Logothetis et al. 2012).

The strong activation of PFC following SWRs during sleep and the data from the primate fMRI study suggests that interaction between the two regions at the time of SWRs could be a mechanism where, during waking behavior, reactivated representations from the hippocampus are used for deliberation. To understand how this might work, it is important to consider that one function of the PFC that is especially relevant for deliberation is its capacity to temporarily maintain representations, referred to as working memory (GoldmanRakic 1995). In tasks during which a subject is required to memorize a cue over a delay, neurons in the PFC become active during the delay (Fuster and Alexander 1971) and the pattern of activity is contingent on the context of the task (Kubota and Niki 1971; Romo et al. 1999).

This mechanism could provide the solution to temporarily storing representations, which are then used for decision making (Curtis and Lee 2010). Using the W-track alternation task as an example, the rat has to choose the opposite arm to the previously visited one. In order to deliberate, we hypothesize the brain needs to maintain at least two types of representations: the previously visited arm and also the potential choice options for the upcoming decision. In this context, the PFC would become a buffer for active memory traces that must remain accessible at the time of decision making. Representations reflecting previously chosen options have already been observed in the PFC (Sul et al. 2010). This suggests that a memory trace of the just visited arm, in the form of a unique ensemble of PFC neurons, 
could also be maintained in the PFC during deliberation for the next choice. Representation of additional possible future choices would come from the hippocampus during SWRs. For example, as the rat is about to make the next outbound decision, the hippocampus could reactivate a sequence of place cells representing a trajectory of one of the possible arms (Figure 3). A subset of these reactivated pyramidal cells will have projections to the PFC and act as the conduit of patterned information. In this case the integrity of patterned information from the hippocampus in the form of cell ensembles representing precise trajectories, would have to be preserved in the PFC. On the W-track, even though the two possible outbound trajectories share a common middle arm, the hippocampal replay for each of the arms will consist of overlapping cells but also non-overlapping cells that represent the outer arms. Thus the overall hippocampal representation for each of the potential trajectories is different and could be distinct enough to modulate different subsets of PFC neurons to form a distinct PFC representation for each potential trajectory. We note, however, that exactly how the sequential activation of hippocampal cells associated with memory replay would engage PFC cells remains unclear; it could be that each trajectory is represented by a distributed but non-sequential PFC pattern, for example.

Whatever the nature of the representation, we would expect that PFC computations related to rule learning (Euston et al. 2012) would then be employed to evaluate the specific option from the hippocampus. The rule of the $\mathrm{W}$-track alternation task is to choose the arm not visited in the last trial when making an outbound decision. Learning is required to formulate this rule over time but any stage during learning, an imperfect rule based on previous experiences could be sufficient to evaluate the choices provided by the hippocampus. The PFC could apply the rule when comparing the reactivated trajectory to the previous trajectory in working memory and decide whether the reactivated trajectory is the correct choice.

More generally, evaluation of choice options is a critical part of deliberation. In the W-track alternation task, evaluation of each trajectory alternative means whether it conforms to the alternation rule. However, deliberation may involve alternatives that are not strictly correct or incorrect, but differ in terms of desirability. Evaluation of these alternatives implies comparing each one in order to find the most appropriate choice. The parameters involved in determining the best alternative include expected reward, perceived cost and uncertainty; all of which are influenced by the internal behavioral state, such as motivation, at the time of decision-making. Activity correlated with these decision parameters has been found in the frontal cortices, including the PFC (Sugrue et al. 2005; Padoa-Schioppa and Assad 2006; Mainen and Kepecs 2009; Sul et al. 2010; Rushworth et al. 2011; Wallis 2011).

Additionally, the PFC is reciprocally connected to the striatum (Groenewegen et al. 1997; Vertes 2004), which is involved in forming action-outcome associations (Penner and Mizumori 2012). The ventral striatum in particular is thought to direct the evaluation of actions in instrumental learning. Further, SWRs trigger both changes in activity in various regions in the frontal cortices (Logothetis et al. 2012) and reactivation of reward associated firing in the ventral striatum (Lansink et al. 2009). We therefore suggest a potential evaluative mechanism: a reactivated trajectory in the hippocampus could reinstate associated representations across these cortical and striatal regions. This global reactivation could occur during deliberation, akin to simulating the result of choosing that option, thus generating an 
overall evaluation signal that is used to make the decision. Each alternative is evaluated until one reaches a decision threshold.

We note that the hypotheses above posit that choices are evaluated in series, rather than in parallel. This one experience per SWR model predicts that a series of SWRs serve to recall multiple choices that can be compared. That possibility is based in part on the available evidence, which suggests that replayed sequences resemble individual trajectories rather than a mixture (Karlsson and Frank 2009). This model would require the brain network evaluating these options to maintain concurrent representations of all the options at the time of the evaluation process in order to select the most appropriate one. Maintaining multiple concurrent representations in the same network without interference is also non-trivial. However, a recent primate study hints at such a mechanism. Multiple sensory input could be simultaneously represented by the PFC network while the decision could be selectively made on a particular subset of the representation (Mante et al. 2013). The possibility that multiple options are evaluated in parallel would have the benefit of promoting faster decision-making.

Finally, while we have focused on the potential mechanisms for hippocampal input to influence PFC activity, feedback from the PFC may also modulate the hippocampus during deliberation. Previous work has demonstrated a PFC - hippocampus interaction, where lesioning and pharmacological inactivation of PFC activity affects hippocampal place fields (Kyd and Bilkey 2003; Kyd and Bilkey 2005; Hok et al. 2013). While it is unclear if and how PFC feedback maybe involved specifically in deliberation, two pathways have been identified that may relay information from the PFC to the hippocampus. The PFC projects directly to the entorhinal cortex (Vertes 2004) and also indirectly via the nucleus reuniens, situated in the midline of the thalamus (Hoover and Vertes 2012; Cassel et al. 2013; Varela et al. 2013). These may provide the anatomical substrates for feedback from the PFC, but further work will be required to understand the role of these projections in deliberative behaviors.

\section{Conclusion}

Decisions often involve the selection of one option from many alternatives. In this process memory of outcomes of past experience is critical in guiding future choices, particularly in situations, such as learning, where deliberation is beneficial. Based on the criteria for patterns of neural activity expected for a deliberative process, we suggest that hippocampal replay during SWRs is a neurophysiological mechanism underlying internal exploration and evaluation of choices during deliberation. It is entirely possible alternative deliberation mechanisms involving the hippocampus and PFC exist, particularly during periods of active locomotion when SWRs occur less frequently. Through its interaction with regions such the PFC, hippocampal replay could engage other networks in evaluating potential choice options on a timescale appropriate for making decisions. 


\section{Acknowledgments}

Preparation of the manuscript was supported by the Jane Coffin Childs Memorial Fund for Medical Research (J.Y.Y.) and the National Institute of Mental Health R01MH090188 (L.M.F.). We thank Gideon Rothschild and Kenneth Kay for comments on the manuscript.

\section{References}

Addis DR, Moscovitch M, McAndrews MP. Consequences of hippocampal damage across the autobiographical memory network in left temporal lobe epilepsy. Brain. 2007; 130:2327-2342. [PubMed: 17681983]

Battaglia FP, Sutherland GR, McNaughton BL. Hippocampal sharp wave bursts coincide with neocortical "up-state" transitions. LearnMem. 2004; 11:697-704.

Benchenane K, Peyrache A, Khamassi M, Tierney PL, Gioanni Y, Battaglia FP, Wiener SI. Coherent theta oscillations and reorganization of spike timing in the hippocampal- prefrontal network upon learning. Neuron. 2010; 66:921-936. [PubMed: 20620877]

Buckner RL. The role of the hippocampus in prediction and imagination. AnnuRevPsychol. 2010; 61:27-28.

Buzsaki G. Hippocampal sharp waves: their origin and significance. Brain Res. 1986; 398:242-252. [PubMed: 3026567]

Buzsaki G. The hippocampo-neocortical dialogue. CerebCortex. 1996; 6:81-92.

Buzsaki G. Theta oscillations in the hippocampus. Neuron. 2002; 33:325-340. [PubMed: 11832222]

Calhoun, JB. The ecology and sociology of the Norway rat. U.S. Dept. of Health, Education, and Welfare, Public Health Service; Bethesda, Md: 1963.

Carr DB, Sesack SR. Hippocampal afferents to the rat prefrontal cortex: synaptic targets and relation to dopamine terminals. JComp Neurol. 1996; 369:1-15. [PubMed: 8723699]

Carr MF, Jadhav SP, Frank LM. Hippocampal replay in the awake state: a potential substrate for memory consolidation and retrieval. Nat Neurosci. 2011; 14:147-153. [PubMed: 21270783]

Cassel JC, Pereira de Vasconcelos A, Loureiro M, Cholvin T, Dalrymple-Alford JC, Vertes RP. The reuniens and rhomboid nuclei: Neuroanatomy, electrophysiological characteristics and behavioral implications. Prog Neurobiol. 2013; 111:34-52. [PubMed: 24025745]

Cenquizca LA, Swanson LW. Spatial organization of direct hippocampal field CA1 axonal projections to the rest of the cerebral cortex. Brain ResRev. 2007; 56:1-26.

Cheng S, Frank LM. New experiences enhance coordinated neural activity in the hippocampus. Neuron. 2008; 57:303-313. [PubMed: 18215626]

Chudasama Y. Animal models of prefrontal-executive function. Behav Neurosci. 2011; 125:327-343. [PubMed: 21639603]

Csicsvari J, Hirase H, Mamiya A, Buzsaki G. Ensemble patterns of hippocampal CA3-CA1 neurons during sharp wave-associated population events. Neuron. 2000; 28:585-594. [PubMed: 11144366]

Curtis CE, Lee D. Beyond working memory: the role of persistent activity in decision making. Trends Cogn Sci. 2010; 14:216-222. [PubMed: 20381406]

Davidson TJ, Kloosterman F, Wilson MA. Hippocampal replay of extended experience. Neuron. 2009; 63:497-507. [PubMed: 19709631]

Degenetais E, Thierry AM, Glowinski J, Gioanni Y. Synaptic influence of hippocampus on pyramidal cells of the rat prefrontal cortex: an in vivo intracellular recording study. Cereb Cortex. 2003; 13:782-792. [PubMed: 12816894]

Diba K, Buzsaki G. Forward and reverse hippocampal place-cell sequences during ripples. Nat Neurosci. 2007; 10:1241-1242. [PubMed: 17828259]

Diekelmann S, Born J. Slow-wave sleep takes the leading role in memory reorganization. NatRevNeurosci. 2010; 11:218.

Dudai Y, Carruthers M. The Janus face of Mnemosyne. Nature. 2005; 434:567. [PubMed: 15800602]

Dupret D, O'Neill J, Pleydell-Bouverie B, Csicsvari J. The reorganization and reactivation of hippocampal maps predict spatial memory performance. NatNeurosci. 2010; 13:995-1002. 
Eichenbaum H, Dudchenko P, Wood E, Shapiro M, Tanila H. The hippocampus, memory, and place cells: is it spatial memory or a memory space? Neuron. 1999; 23:209-226. [PubMed: 10399928]

Eichenbaum H, Kuperstein M, Fagan A, Nagode J. Cue-sampling and goal-approach correlates of hippocampal unit activity in rats performing an odordiscrimination task. J Neurosci. 1987; 7:716732. [PubMed: 3559709]

Euston DR, Gruber AJ, McNaughton BL. The role of medial prefrontal cortex in memory and decision making. Neuron. 2012; 76:1057-1070. [PubMed: 23259943]

Euston DR, Tatsuno M, McNaughton BL. Fast-forward playback of recent memory sequences in prefrontal cortex during sleep. Science. 2007; 318:1147-1150. [PubMed: 18006749]

Ferbinteanu J, Ray C, McDonald RJ. Both dorsal and ventral hippocampus contribute to spatial learning in Long-Evans rats. NeurosciLett. 2003; 345:131-135.

Floresco SB, Seamans JK, Phillips AG. Selective roles for hippocampal, prefrontal cortical, and ventral striatal circuits in radial-arm maze tasks with or without a delay. J Neurosci. 1997; 17:1880-1890. [PubMed: 9030646]

Foster DJ, Wilson MA. Reverse replay of behavioural sequences in hippocampal place cells during the awake state. Nature. 2006; 440:680-683. [PubMed: 16474382]

Frank LM, Brown EN, Wilson M. Trajectory encoding in the hippocampus and entorhinal cortex. Neuron. 2000; 27:169-178. [PubMed: 10939340]

Frankland PW, Bontempi B. The organization of recent and remote memories. Nat Rev Neurosci. 2005; 6:119-130. [PubMed: 15685217]

Fujisawa S, Amarasingham A, Harrison MT, Buzsaki G. Behavior-dependent short-term assembly dynamics in the medial prefrontal cortex. Nat Neurosci. 2008; 11:823-833. [PubMed: 18516033]

Fuster JM, Alexander GE. Neuron activity related to short-term memory. Science. 1971; 173:652-654. [PubMed: 4998337]

Gabbott P, Headlam A, Busby S. Morphological evidence that CA1 hippocampal afferents monosynaptically innervate PV-containing neurons and NADPH-diaphorase reactive cells in the medial prefrontal cortex (Areas 25/32) of the rat. Brain Res. 2002; 946:314-322. [PubMed: 12137936]

Girardeau G, Zugaro M. Hippocampal ripples and memory consolidation. Curr Opin Neurobiol. 2011; 21:452-459. [PubMed: 21371881]

Goldman-Rakic PS. Cellular basis of working memory. Neuron. 1995; 14:477-485. [PubMed: 7695894]

Groenewegen HJ, Wright CI, Uylings HB. The anatomical relationships of the prefrontal cortex with limbic structures and the basal ganglia. J Psychopharmacol. 1997; 11:99-106. [PubMed: 9208373]

Gupta AS, van der Meer MA, Touretzky DS, Redish AD. Hippocampal replay is not a simple function of experience. Neuron. 2010; 65:695-705. [PubMed: 20223204]

Gupta AS, van der Meer MA, Touretzky DS, Redish AD. Segmentation of spatial experience by hippocampal theta sequences. Nat Neurosci. 2012; 15:1032-1039. [PubMed: 22706269]

Hasselmo ME, Stern CE. Theta rhythm and the encoding and retrieval of space and time. Neuroimage. 2013

Hok V, Chah E, Save E, Poucet B. Prefrontal cortex focally modulates hippocampal place cell firing patterns. J Neurosci. 2013; 33:3443-3451. [PubMed: 23426672]

Hoover WB, Vertes RP. Collateral projections from nucleus reuniens of thalamus to hippocampus and medial prefrontal cortex in the rat: a single and double retrograde fluorescent labeling study. Brain Struct Funct. 2012; 217:191-209. [PubMed: 21918815]

Hyman JM, Zilli EA, Paley AM, Hasselmo ME. Medial prefrontal cortex cells show dynamic modulation with the hippocampal theta rhythm dependent on behavior. Hippocampus. 2005; 15:739-749. [PubMed: 16015622]

Jackson JC, Johnson A, Redish AD. Hippocampal sharp waves and reactivation during awake states depend on repeated sequential experience. J Neurosci. 2006; 26:12415-12426. [PubMed: 17135403]

Jadhav SP, Kemere C, German PW, Frank LM. Awake hippocampal sharp-wave ripples support spatial memory. Science. 2012; 336:1454-1458. [PubMed: 22555434] 
Jay TM, Glowinski J, Thierry AM. Selectivity of the hippocampal projection to the prelimbic area of the prefrontal cortex in the rat. Brain Res. 1989; 505:337-340. [PubMed: 2598054]

Jay TM, Thierry AM, Wiklund L, Glowinski J. Excitatory amino acid pathway from the hippocampus to the prefrontal cortex: contribution of AMPA receptors in hippocampo-prefrontal cortex transmission. Eur J Neurosci. 1992; 4:1285-1295. [PubMed: 12106392]

Johnson A, Redish AD. Neural ensembles in CA3 transiently encode paths forward of the animal at a decision point. Journal of Neuroscience. 2007; 27:12176-12189. [PubMed: 17989284]

Jones MW, Wilson MA. Phase precession of medial prefrontal cortical activity relative to the hippocampal theta rhythm. Hippocampus. 2005a; 15:867-873. [PubMed: 16149084]

Jones MW, Wilson MA. Theta rhythms coordinate hippocampal-prefrontal interactions in a spatial memory task. PLoSBiol. 2005b; 3:e402.

Karlsson MP, Frank LM. Network Dynamics Underlying the Formation of Sparse, Informative Representations in the Hippocampus. Journal of Neuroscience. 2008; 28:14271-14281. [PubMed: 19109508]

Karlsson MP, Frank LM. Awake replay of remote experiences in the hippocampus. Nat Neurosci. 2009; 12:913-918. [PubMed: 19525943]

Kemere C, Carr MF, Karlsson MP, Frank LM. Rapid and Continuous Modulation of Hippocampal Network State during Exploration of New Places. PLoS One. 2013; 8:e73114. [PubMed: 24023818]

Kesner RP. Retrospective and prospective coding of information: role of the medial prefrontal cortex. Exp Brain Res. 1989; 74:163-167. [PubMed: 2924832]

Kesner RP, Churchwell JC. An analysis of rat prefrontal cortex in mediating executive function. Neurobiol LearnMem. 2011; 96:417-431.

Klausberger T, Somogyi P. Neuronal diversity and temporal dynamics: the unity of hippocampal circuit operations. Science. 2008; 321:53-57. [PubMed: 18599766]

Kubota K, Niki H. Prefrontal cortical unit activity and delayed alternation performance in monkeys. J Neurophysiol. 1971; 34:337-347. [PubMed: 4997822]

Kudrimoti HS, Barnes CA, McNaughton BL. Reactivation of hippocampal cell assemblies: effects of behavioral state, experience, and EEG dynamics. J Neurosci. 1999; 19:4090-4101. [PubMed: 10234037]

Kyd RJ, Bilkey DK. Prefrontal cortex lesions modify the spatial properties of hippocampal place cells. Cereb Cortex. 2003; 13:444-451. [PubMed: 12679291]

Kyd RJ, Bilkey DK. Hippocampal place cells show increased sensitivity to changes in the local environment following prefrontal cortex lesions. Cereb Cortex. 2005; 15:720-731. [PubMed: 15371292]

Lansink CS, Goltstein PM, Lankelma JV, McNaughton BL, Pennartz CM. Hippocampus leads ventral striatum in replay of place-reward information. PLoSBiol. 2009; 7:e1000173.

Laroche S, Jay TM, Thierry AM. Long-term potentiation in the prefrontal cortex following stimulation of the hippocampal CA1/subicular region. Neurosci Lett. 1990; 114:184-190. [PubMed: 2395531]

Lee AK, Wilson MA. Memory of sequential experience in the hippocampus during slow wave sleep. Neuron. 2002; 36:1183-1194. [PubMed: 12495631]

Logothetis NK, Eschenko O, Murayama Y, Augath M, Steudel T, Evrard HC, Besserve M, Oeltermann A. Hippocampal-cortical interaction during periods of subcortical silence. Nature. 2012; 491:547-553. [PubMed: 23172213]

MacDonald C, Lepage K, Eden U, Eichenbaum H. Hippocampal Time Cells Bridge the Gap in Memory for Discontiguous Events. Neuron. 2011; 71:737-749. [PubMed: 21867888]

Mainen ZF, Kepecs A. Neural representation of behavioral outcomes in the orbitofrontal cortex. CurrOpinNeurobiol. 2009; 19:84-91.

Mante V, Sussillo D, Shenoy KV, Newsome WT. Context-dependent computation by recurrent dynamics in prefrontal cortex. Nature. 2013; 503:78-84. [PubMed: 24201281]

Molle M, Yeshenko O, Marshall L, Sara SJ, Born J. Hippocampal sharp wave-ripples linked to slow oscillations in rat slow-wave sleep. J Neurophysiol. 2006; 96:62-70. [PubMed: 16611848]

Neurobiol Learn Mem. Author manuscript; available in PMC 2016 January 01. 
Muenzinger KF. Vicarious trial and error at a point of choice: I. A general survey of its relation to learning efficiency. Pedagogical Seminary and Journal of Genetic Psychology. 1938; 53:75.

Muenzinger KF, Gentry E. Tone discrimination in white rats. J Comp Psychol. 1931; 12:195-206.

Nadel L, Ryan L, Hayes SM, Gilboa A, Moscovitch M. The role of the hippocampal complex in longterm episodic memory. Int Congr Ser. 2003; 1250:215-234.

O'Keefe J, Dostrovsky J. The hippocampus as a spatial map. Preliminary evidence from unit activity in the freely-moving rat. Brain Res. 1971; 34:171-175. [PubMed: 5124915]

O'Keefe J, Recce ML. Phase relationship between hippocampal place units and the EEG theta rhythm. Hippocampus. 1993; 3:317-330. [PubMed: 8353611]

O'Neill J, Pleydell-Bouverie B, Dupret D, Csicsvari J. Play it again: reactivation of waking experience and memory. Trends Neurosci. 2010; 33:220-229. [PubMed: 20207025]

O'Neill J, Senior T, Csicsvari J. Place-selective firing of CA1 pyramidal cells during sharp wave/ripple network patterns in exploratory behavior. Neuron. 2006; 49:143-155. [PubMed: 16387646]

O'Neill J, Senior TJ, Allen K, Huxter JR, Csicsvari J. Reactivation of experience-dependent cell assembly patterns in the hippocampus. NatNeurosci. 2008; 11:209-215.

Padoa-Schioppa C, Assad JA. Neurons in the orbitofrontal cortex encode economic value. Nature. 2006; 441:223-226. [PubMed: 16633341]

Pastalkova E, Itskov V, Amarasingham A, Buzsaki G. Internally generated cell assembly sequences in the rat hippocampus. Science. 2008; 321:1322-1327. [PubMed: 18772431]

Penner MR, Mizumori SJ. Neural systems analysis of decision making during goal-directed navigation. ProgNeurobiol. 2012; 96:96-135.

Peyrache A, Battaglia FP, Destexhe A. Inhibition recruitment in prefrontal cortex during sleep spindles and gating of hippocampal inputs. ProcNatlAcadSciUSA. 2011; 108:17207-17212.

Pfeiffer BE, Foster DJ. Hippocampal place-cell sequences depict future paths to remembered goals. Nature. 2013

Prasad JA, Chudasama Y. Viral tracing identifies parallel disynaptic pathways to the hippocampus. J Neurosci. 2013; 33:8494-8503. [PubMed: 23658186]

Ragozzino ME, Adams S, Kesner RP. Differential involvement of the dorsal anterior cingulate and prelimbic-infralimbic areas of the rodent prefrontal cortex in spatial working memory. BehavNeurosci. 1998; 112:293-303.

Remondes M, Wilson MA. Cingulate-hippocampus coherence and trajectory coding in a sequential choice task. Neuron. 2013; 80:1277-1289. [PubMed: 24239123]

Romo R, Brody CD, Hernandez A, Lemus L. Neuronal correlates of parametric working memory in the prefrontal cortex. Nature. 1999; 399:470-473. [PubMed: 10365959]

Rushworth MF, Noonan MP, Boorman ED, Walton ME, Behrens TE. Frontal cortex and rewardguided learning and decision-making. Neuron. 2011; 70:1054-1069. [PubMed: 21689594]

Sakurai Y. Hippocampal and neocortical cell assemblies encode memory processes for different types of stimuli in the rat. J Neurosci. 1996; 16:2809-2819. [PubMed: 8786455]

Schacter DL, Addis DR. Constructive memory: the ghosts of past and future. Nature. 2007; 445:27. [PubMed: 17203045]

Schacter DL, Addis DR, Buckner RL. Remembering the past to imagine the future: the prospective brain. Nat Rev Neurosci. 2007; 8:657-661. [PubMed: 17700624]

Seamans JK, Lapish CC, Durstewitz D. Comparing the prefrontal cortex of rats and primates: insights from electrophysiology. NeurotoxRes. 2008; 14:249-262.

Siapas AG, Wilson MA. Coordinated interactions between hippocampal ripples and cortical spindles during slow-wave sleep. Neuron. 1998; 21:1123-1128. [PubMed: 9856467]

Singer AC, Carr MF, Karlsson MP, Frank LM. Hippocampal SWR Activity Predicts Correct Decisions during the Initial Learning of an Alternation Task. Neuron. 2013; 77:1163-1173. [PubMed: 23522050]

Singer AC, Frank LM. Rewarded outcomes enhance reactivation of experience in the hippocampus. Neuron. 2009; 64:910-921. [PubMed: 20064396]

Sirota A, Csicsvari J, Buhl D, Buzsaki G. Communication between neocortex and hippocampus during sleep in rodents. Proc Natl Acad Sci U S A. 2003; 100:2065-2069. [PubMed: 12576550] 
Skaggs WE, McNaughton BL. Replay of neuronal firing sequences in rat hippocampus during sleep following spatial experience. Science. 1996; 271:1870-1873. [PubMed: 8596957]

Squire LR. Memory and the hippocampus: a synthesis from findings with rats, monkeys, and humans. PsycholRev. 1992; 99:195-231. published erratum appears in Psychol Rev 1992 Jul;99(3):582.

Sugrue LP, Corrado GS, Newsome WT. Choosing the greater of two goods: neural currencies for valuation and decision making. Nat RevNeurosci. 2005; 6:363-375.

Sul JH, Kim H, Huh N, Lee D, Jung MW. Distinct roles of rodent orbitofrontal and medial prefrontal cortex in decision making. Neuron. 2010; 66:449-460. [PubMed: 20471357]

Swanson LW, Cowan WM. An autoradiographic study of the organization of the efferent connections of the hippocampal formation in the rat. JComp Neurol. 1977; 172:49-84. [PubMed: 65364]

Takita M, Fujiwara SE, Izaki Y. Functional structure of the intermediate and ventral hippocampoprefrontal pathway in the prefrontal convergent system. J Physiol Paris. 2013; 107:441-447. [PubMed: 23719128]

Telle H. Beitrag zur Kenntnis der Verhaltensweise von Ratten, vergleichend dargestellt bei Rattus norvegicus und Rattus rattus. Zeitschrift für angewandte Zoologie. 1966; 53:129-196.

Tierney PL, Degenetais E, Thierry AM, Glowinski J, Gioanni Y. Influence of the hippocampus on interneurons of the rat prefrontal cortex. Eur J Neurosci. 2004; 20:514-524. [PubMed: 15233760]

Tolman EC. The determiners of behavior at a choice point. Psychol Rev. 1938; 45:1-41.

Tolman EC. Cognitive maps in rats and men. PsycholRev. 1948; 55:189-208.

Tolman EC, Ritchie BF, Kalish D. Studies in spatial learning: Orientation and the short-cut. J Exp Psychol. 1946; 36:13-24. [PubMed: 21015338]

Uylings HB, Groenewegen HJ, Kolb B. Do rats have a prefrontal cortex? Behav Brain Res. 2003; 146:3-17. [PubMed: 14643455]

Uylings HB, van Eden CG. Qualitative and quantitative comparison of the prefrontal cortex in rat and in primates, including humans. Prog Brain Res. 1990; 85:31-62. [PubMed: 2094901]

Van Groen T, Wyss JM. Extrinsic projections from area CA1 of the rat hippocampus: olfactory, cortical, subcortical, and bilateral hippocampal formation projections. J Comp Neurol. 1990; 302:515-528. [PubMed: 1702115]

Varela C, Kumar S, Yang JY, Wilson MA. Anatomical substrates for direct interactions between hippocampus, medial prefrontal cortex, and the thalamic nucleus reuniens. Brain StructFunct. 2013

Vertes RP. Differential projections of the infralimbic and prelimbic cortex in the rat. Synapse. 2004; 51:32-58. [PubMed: 14579424]

Verwer RW, Meijer RJ, Van Uum HF, Witter MP. Collateral projections from the rat hippocampal formation to the lateral and medial prefrontal cortex. Hippocampus. 1997; 7:397-402. [PubMed: 9287079]

Wallis JD. Cross-species studies of orbitofrontal cortex and value-based decisionmaking. Nat Neurosci. 2011; 15:13-19. [PubMed: 22101646]

Wible CG, Findling RL, Shapiro M, Lang EJ, Crane S, Olton DS. Mnemonic correlates of unit activity in the hippocampus. Brain Res. 1986; 399:97-110. [PubMed: 3099978]

Wiener SI, Paul CA, Eichenbaum H. Spatial and behavioral correlates of hippocampal neuronal activity. Journal of Neuroscience. 1989; 9:2737-2763. [PubMed: 2769364]

Wierzynski CM, Lubenov EV, Gu M, Siapas AG. State-dependent spike-timing relationships between hippocampal and prefrontal circuits during sleep. Neuron. 2009; 61:587-596. [PubMed: 19249278]

Wilson MA, McNaughton BL. Reactivation of hippocampal ensemble memories during sleep. Science. 1994; 265:676-679. [PubMed: 8036517]

Wood ER, Dudchenko PA, Robitsek RJ, Eichenbaum H. Hippocampal neurons encode information about different types of memory episodes occurring in the same location. Neuron. 2000; 27:623633. [PubMed: 11055443] 

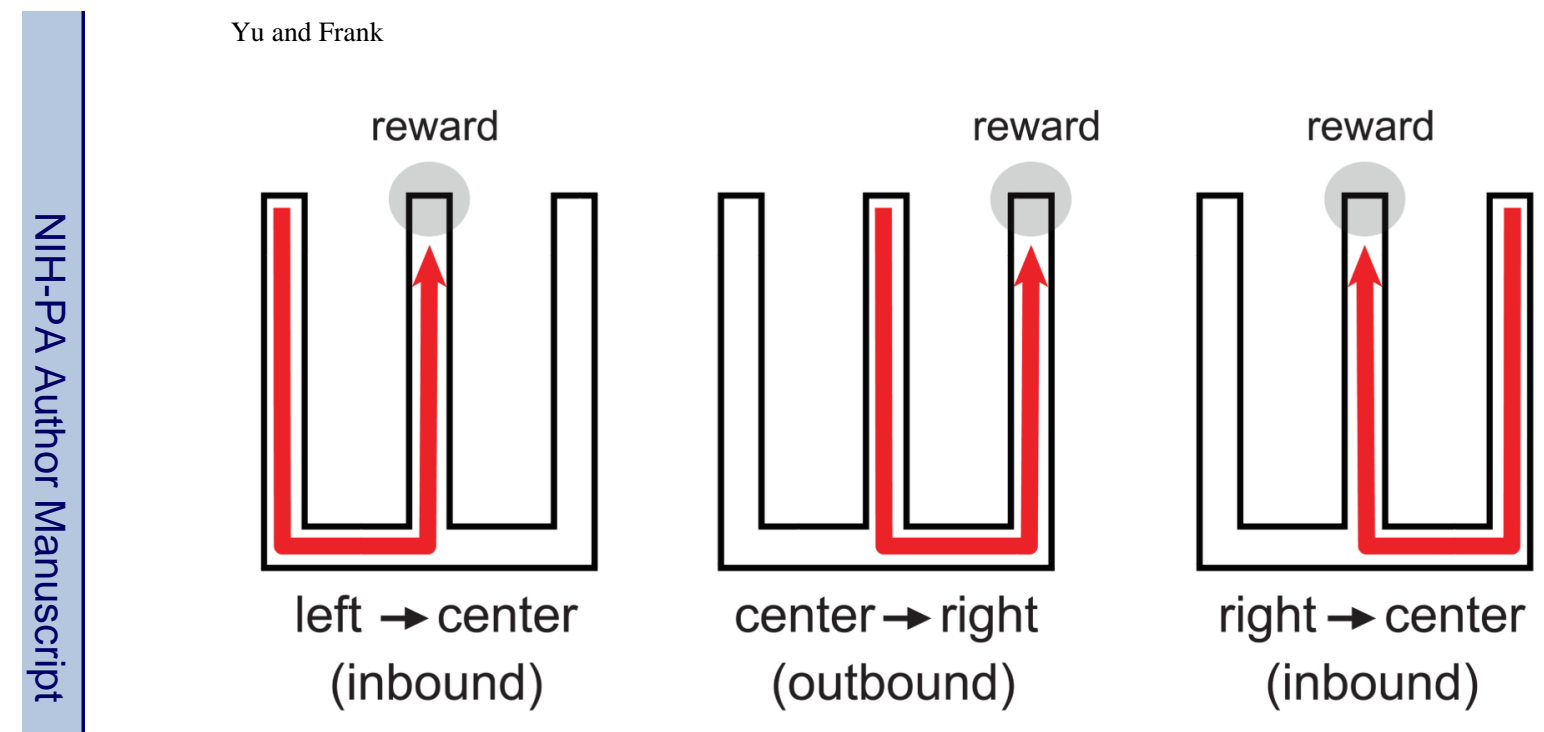

reward

Figure 1.

The W-track alternation task. To perform the task and continuously receive reward, the rat must visit the arms in an alternating pattern. An inbound trial starts on the outside arm and ends on the center arm. An outbound trial starts in the center arm and ends on the outside arm. 

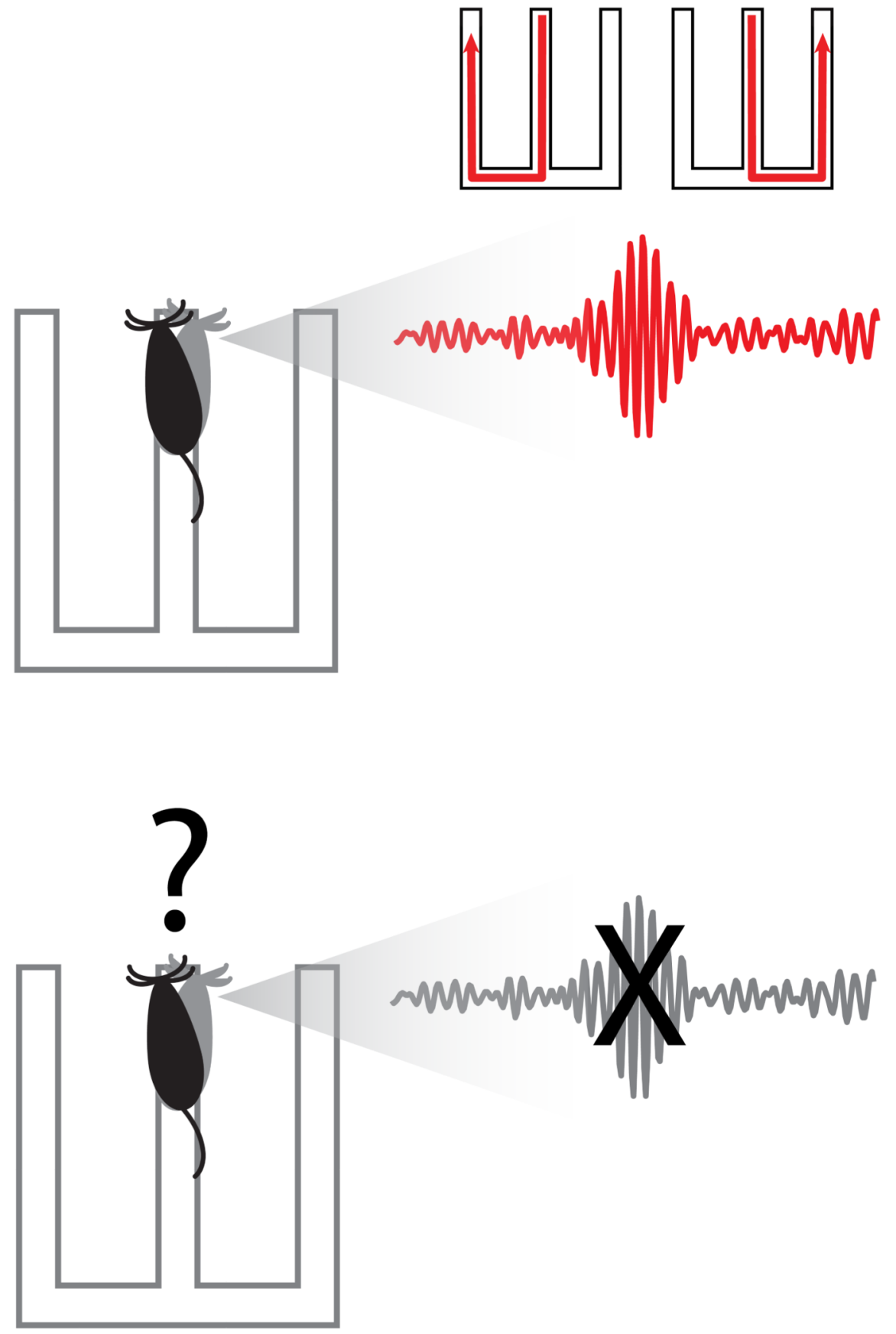

Figure 2.

SWRs could provide choice options for deciding which outside arm to visit when making an outbound decision. Potential trajectories are reactivated during SWRs during the decisionmaking period. When SWRs are disrupted, the choice options may not be available at the time of deliberation, impairing the decision-making process. 
Option
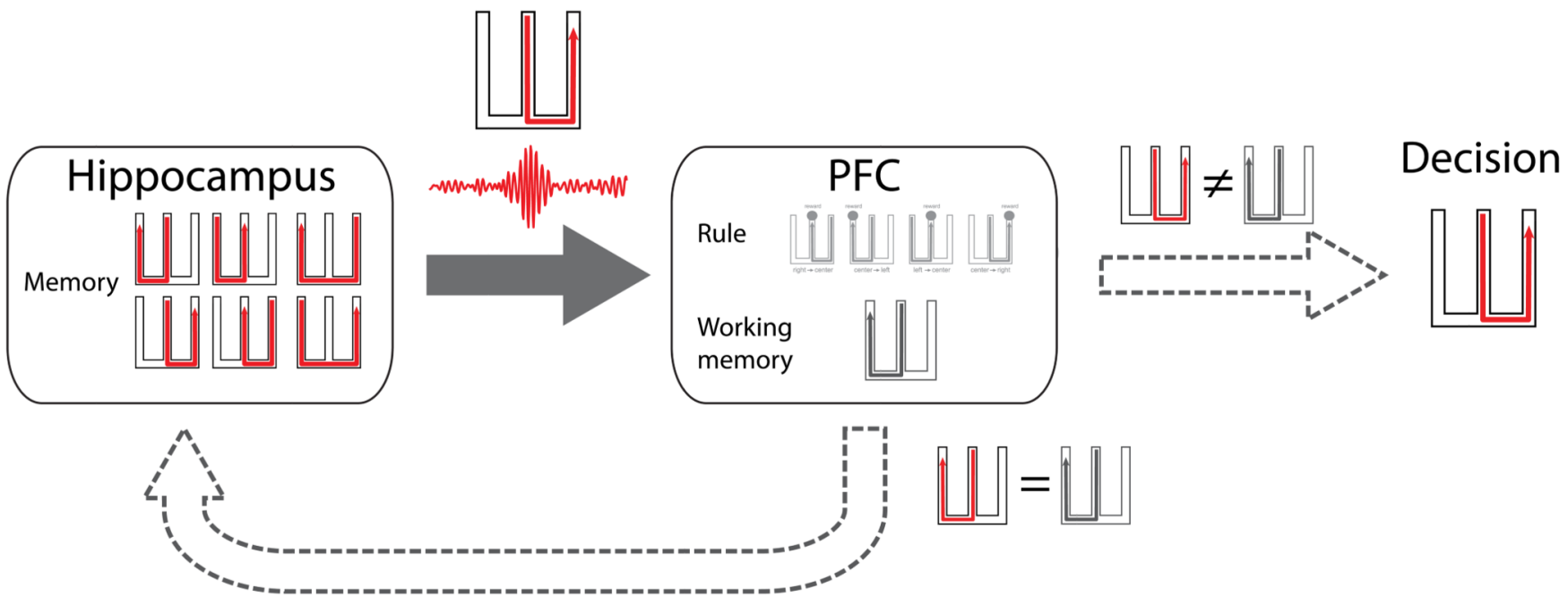

\section{Reiterate}

Figure 3.

A proposed mechanism for deliberation in the $\mathrm{W}$-track alternation task. The hippocampus recalls alternative choice trajectories from memory and provides this serially to the PFC. The PFC compares the option against a rule for the task and a representation of the previous trajectory stored in working memory. If the comparison conforms to the rule, a decision is made to accept that option. In case it does not, this process is reiterated. 